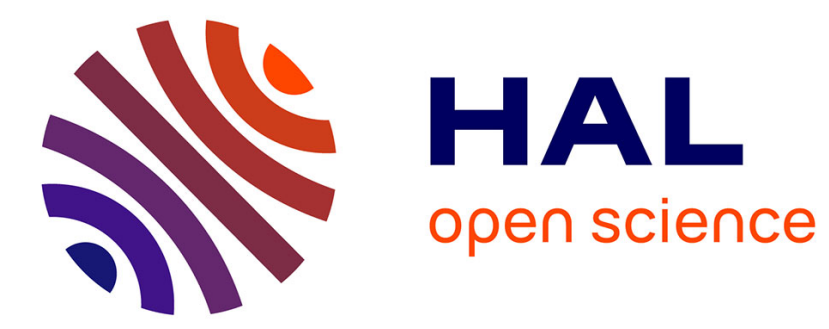

\title{
OPTICAL PROPERTIES OF METASTABLE ONE PHASE Cu-Ag ALLOYS
}

\author{
P. Nilsson, G. Forssell
}

\section{To cite this version:}

P. Nilsson, G. Forssell. OPTICAL PROPERTIES OF METASTABLE ONE PHASE Cu-Ag ALLOYS. Journal de Physique Colloques, 1974, 35 (C4), pp.C4-57-C4-59. 10.1051/jphyscol:1974408 . jpa00215599

\section{HAL Id: jpa-00215599 https://hal.science/jpa-00215599}

Submitted on 1 Jan 1974

HAL is a multi-disciplinary open access archive for the deposit and dissemination of scientific research documents, whether they are published or not. The documents may come from teaching and research institutions in France or abroad, or from public or private research centers.
L'archive ouverte pluridisciplinaire HAL, est destinée au dépôt et à la diffusion de documents scientifiques de niveau recherche, publiés ou non, émanant des établissements d'enseignement et de recherche français ou étrangers, des laboratoires publics ou privés. 


\title{
OPTICAL PROPERTIES OF METASTABLE ONE PHASE Cu-Ag ALLOYS
}

\author{
P. O. NILSSON and G. FORSSELL \\ Department of Physics, Chalmers University \\ of Technology, Fack, S-40220 Gothenburg 5, Sweden
}

\begin{abstract}
Résumé. - La fonction diélectrique complexe des couches minces des alliages de $\mathrm{Cu}-\mathrm{Ag}$ a été déterminée par des mesures de transmission optique. La structure électronique des trois alliages de métal noble-métal noble s'est avérée être qualitativement la même.

Abstract. - The complex dielectric function of thin $\mathrm{Cu}-\mathrm{Ag}$ alloy films has been determined from optical transmittance measurements. The electronic structures of the three noble metal-noble metal alloys are found to be qualitatively the same, in contrary to earlier findings.
\end{abstract}

1. Introduction. - The theory of the electronic structure of substitutionally disordered alloys has been subject to a great interest during the last decade. Comparatively few of the theoretical results have however been correlated with experimental data. Comparisons between model calculations and spectroscopic measurements like optical absorption, photoemission, X-ray emission etc. should be most fruitful. The noble metals are tractable candidates in this connection for two reasons. Firstly, they contain localized states in form of d-bands, for which model calculations have been presented. Secondly, they are suitable from a pure experimental point of view. Data on $\mathrm{Ag}-\mathrm{Au}$ and $\mathrm{Cu}-\mathrm{Au}$ alloys have been reported earlier in literature, while there seems to be no data on concentrated $\mathrm{Cu}-\mathrm{Ag}$ alloys. In the present paper we present the optical absorption of one phase $\mathrm{Cu}-\mathrm{Ag}$ alloys over the whole concentration range and give an interpretation of the observed concentration dependence. The electronic structure of the three noble metal-noble metal alloys will also be discussed.

2. Experimental. - Cu-Ag alloys containing 19, 36, 63 and 84 atomic percent $\mathrm{Cu}$ were produced by melting. A piece of approximately $1 \mathrm{~cm}^{3}$ of an alloy was mounted in a holder in an ultrahigh vacuum chamber. At a pressure in the $10^{-10}$ torr region the sample was filed which caused thin flakes (approx. $0.01 \mathrm{~mm}$ in diameter) of the alloy to fall into a metal box. The box was then tilted so that only a few flakes at a time fell onto a heated tantalum ribbon. In this way the alloys were flash evaporated onto a liquid nitrogen cooled quartz substrate. The pressure was at this stage in the $10^{-9}$ torr region. Metastable, vapour quenched thin films of $200-600 \AA$ thickness were produced in this way. Electron diffraction patterns, taken at room temperature, showed an amorphous structure for the $\mathrm{Cu}_{63} \mathrm{Ag}_{37}$ alloy while the others were found crystalline. Annealing at $400 \mathrm{~K}$ makes amorphous alloy crystalline, while annealing at $500 \mathrm{~K}$ results in a two phase structure for all alloys. These results are in agreement with earlier findings [1].

The optical transmittance of the thin alloy filmquartz substrate sample was recorded continously with a spectrophotometer in the range of 0.5 to $6.2 \mathrm{eV}$ photon energy. For a few photon energies the reflectance was measured which together with the transmittance and the measured film thickness gives the optical constants. These constants were used to estimate extrapolations of the transmittance outside the measured range. Finally the complex dielectric function was evaluated in the whole measured energy range using dispersion analysis on the measured and extrapolated transmittance data [2].

3. Results and discussion. - Figure 1 and 2 show the function $\varepsilon_{2}(v) v^{2}$, where $\varepsilon_{2}(v)$ is the imaginary part of the dielectric function and $v$ the frequency. The function is proportional to the " optical joint density of states». The optical absorption is proportional to $\varepsilon_{2}(v) v$. We observe that on alloying $\mathrm{Cu}$ with $\mathrm{Ag}$ the absorption edge at $2 \mathrm{eV}$ stays approximately constant. Only at high $\mathrm{Ag}$ contents the edge moves to higher photon energies and weakens. The second edge at $4 \mathrm{eV}$ moves slightly to lower energies and increases in strength. No qualitative differences are found between the crystalline and amorphous $\mathrm{Cu}_{63} \mathrm{Ag}_{37}$ alloy.

The absorption spectra of $\mathrm{Cu}$ and $\mathrm{Ag}$ have been analyzed elsewhere $[3,4]$ in detail in terms of the band structure. It is known that the $2 \mathrm{eV}$ edge for $\mathrm{Cu}$ is caused by transitions from the upper part of the d-band complex to the Fermi level. The same is true for Ag except that there is also a contribution from transitions across the conduction band gap around the L-point.

The photon energy at the onset of the edge is plotted versus $\mathrm{Cu}$ content in figure 3. As the contribution from $\mathrm{Cu}$ in diluted $\underline{\mathrm{AgCu}}$ alloys was found very weak 


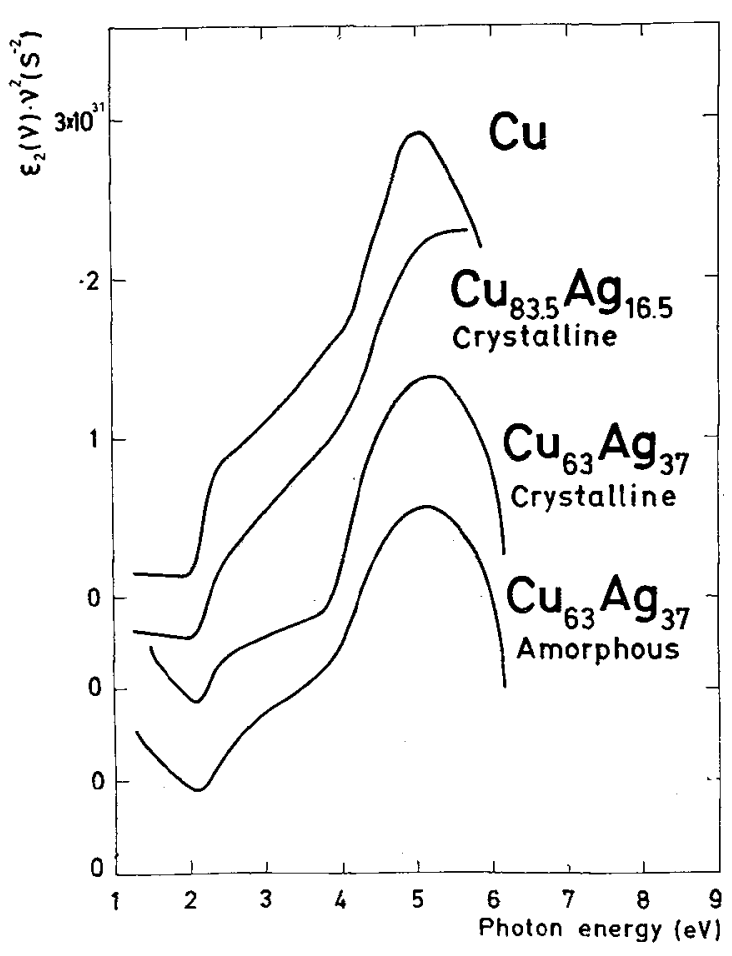

FIG. 1. - Optical joint density of states for Cu-Ag alloys.

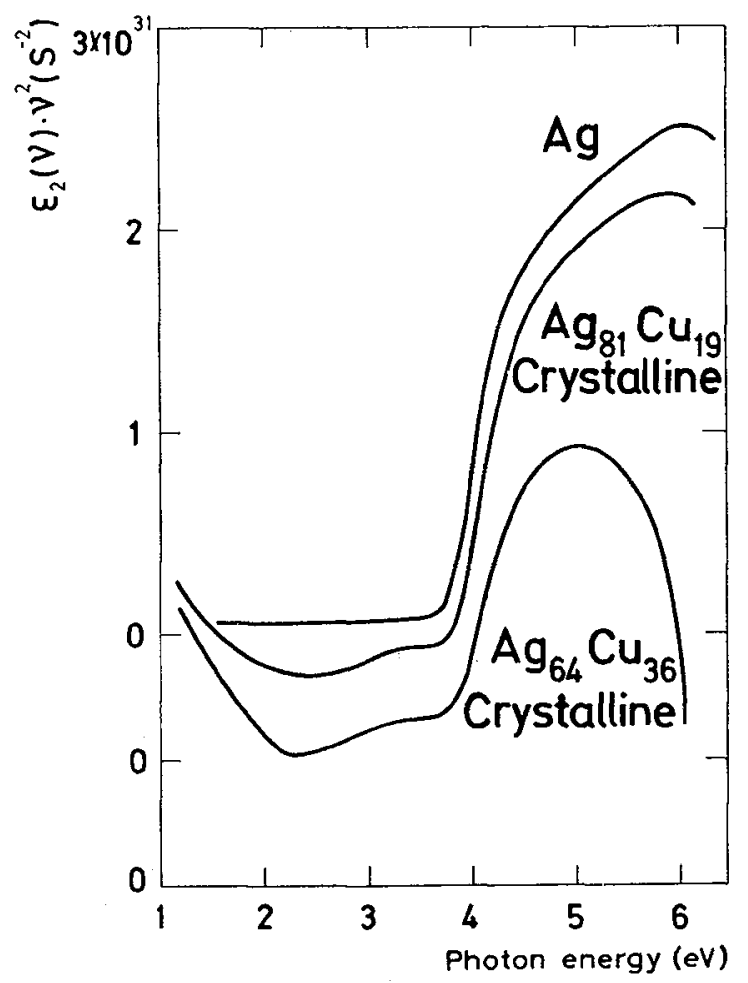

FIg. 2. - Optical joint density of states for $\mathrm{Cu}-\mathrm{Ag}$ alloys.

we have used the differential reflectance data by Beaglehole and Erlbach [5]. From their data we evaluate the $\mathrm{Cu}$ impurity edge to occur at $2.7 \mathrm{eV}$.

For the interpretation of the data in terms of the electronic structure of the alloys we use the highly sim-

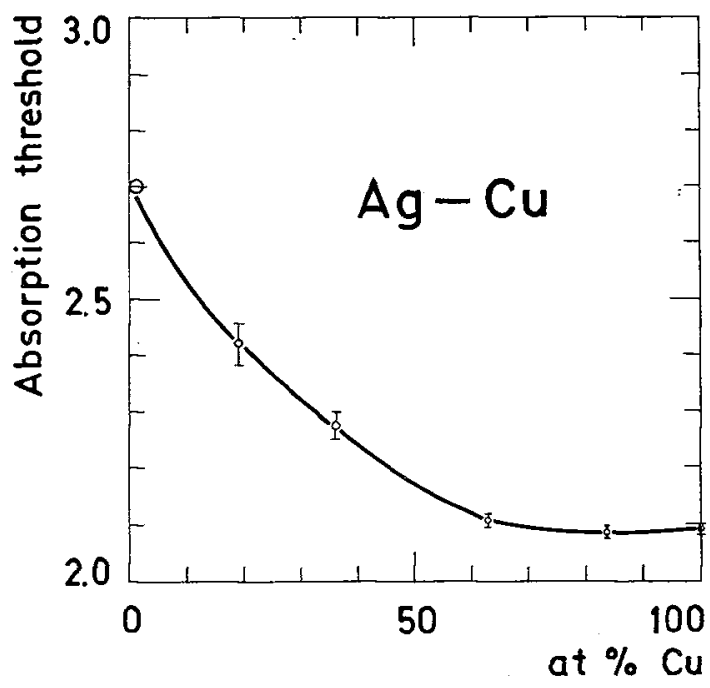

FIG. 3. - The photon energy of the lowest interband absorption edge in $\mathrm{Cu}-\mathrm{Ag}$ alloys as a function of composition.

plified schematic picture of the density of states in figure 4. Suppose that a $\mathrm{CuAg}$ solid solution is formed by diluting $\mathrm{Cu}$ with $\mathrm{Ag}$. The effective width of the $\mathrm{Cu}$ d-band will then decrease with a certain amount $\Delta W_{d}^{C u}$ due to less $\mathrm{Cu} \mathrm{d}$-d overlap on the average. We will throughout this paper disregard from tailing effects from statistical clusters [6] and from s-d and $\mathrm{Cu} \mathrm{d-Ag} \mathrm{d}$ interactions. When the Ag content increases the expected development towards the other dilute limit is shown in figure 4. The $\mathrm{Cu}$ d-band will for low $\mathrm{Cu}$

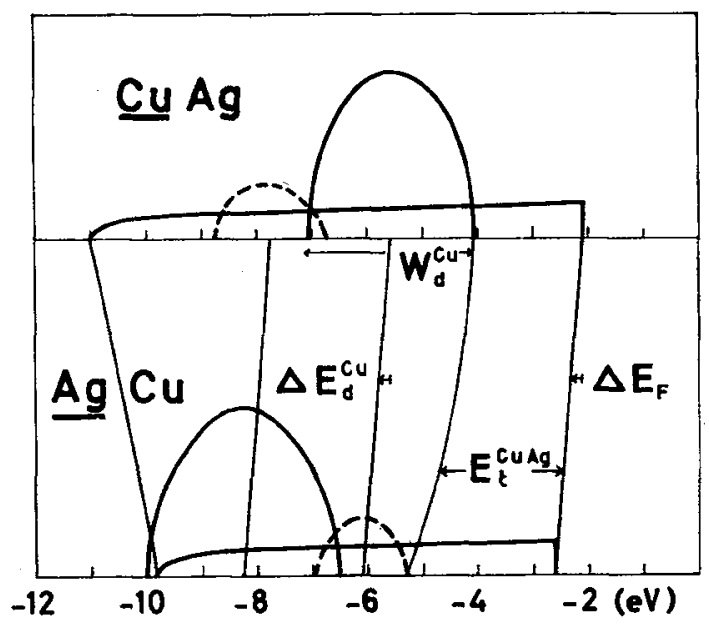

FIG. 4. - Highly schematic picture of the density of states in $\mathrm{Cu}-\mathrm{Ag}$ alloys.

content form an impurity band at the top of the $\mathrm{Ag}$ d-band, shifted $\Delta E_{\mathrm{d}}^{\mathrm{Cu}}$ from the position in pure $\mathrm{Cu}$. The width is determined by the $s-d$ hybridization and spin-orbit splitting and should be of the order of $1 \mathrm{eV}$.

On an absolute energy scale the Fermi level will change on alloying. We have in figure 4 assumed it to be higher in $\mathrm{Cu}$ than in Ag. This would mean a s-p 
charge transfer onto the $\mathrm{Ag}$ atoms with a d-charge compensation flow in the other direction. This would contribute to a shift of the $\mathrm{Cu}$ d-impurity band a certain amount $\Delta E_{\mathrm{d}}^{\mathrm{Cu}}$ to lower energies. The sign of $\Delta E_{\mathrm{F}}$, and thus of $\Delta E_{\mathrm{d}}^{\mathrm{Cu}}$, will however only affect the detailed shape of the curve in figure 3 , not the qualitative behaviour [7]. With the introduced notations the photon energy for the absorption edge can be written in terms of the simple model in figure 4:

$$
h \omega_{\mathrm{t}}^{\mathrm{CuAg}}=h \omega_{\mathrm{t}}^{\mathrm{Cu}}-\Delta E_{\mathrm{F}}+\Delta E_{\mathrm{d}}^{\mathrm{Cu}}+\frac{1}{2} \Delta W_{\mathrm{d}}^{\mathrm{Cu}} .
$$

The data in figures 1-3 are consistent with the given picture of the density of states. It is important to observe that from general considerations $h \omega_{\mathrm{t}}^{\text {CuAg }}$ does not tend to $E_{\mathrm{t}}^{\mathrm{Ag}}$ for low $\mathrm{Cu}$ content. We find

$$
h \omega_{t}^{\mathrm{AgCu}}=2.7 \mathrm{eV} \text { and } h \omega_{\mathrm{t}}^{\mathrm{Ag}}=3.9 \mathrm{eV} .
$$

This comment is particularly important in connection with the interpretation of the optical data [8-11] of the Ag-Au system, which has been assumed [5] to behave differently from the $\mathrm{Cu}-\mathrm{Ag}$ system. It has been deduced by several authors $[5,8,9]$ that the absorption edge moves continuously from the edge in pure $\mathrm{Au}$ to the edge in pure Ag. Such a behaviour has been interpreted in terms at a virtual crystal behaviour [12]. Reexamining the data of $\varepsilon_{2}(\omega)$ we have however found [13] that the threshold is lower in $\mathrm{AgAu}$ than in $\mathrm{Ag}$ with a few tenths of an $\mathrm{eV}$. Thus the " two band model » in figure 4 is valid also for $\mathrm{Ag}-\mathrm{Au}$ alloys, as already pointed out in an earlier publication [14].

Finally we point out the particular behaviour of the $\mathrm{Cu}-\mathrm{Au}$ alloys. The curve corresponding to figure 3 shows a pronounced bump round 35 atomic percent $\mathrm{Cu}[15,13]$. An analysis with the model in figure 4 shows that the $\mathrm{Cu}$ impurity band is entirely inside the $\mathrm{Au}$ band in $\mathrm{AuCu}$. When the $\mathrm{Cu}$ content is increased the upper edge of the $\mathrm{Cu}$ band increases in energy while the Au band edge decreases. At some concentration the $\mathrm{Cu}$ band will penetrate the Au edge, causing the mentioned behaviour in $\varepsilon_{2}(\omega)$.

Calculations [13] within the CPA, using the model by Schwartz et al. [16], can reproduce the observed concentration dependence of the absorption edge in the $\mathrm{Cu}-\mathrm{Ag}$ system. The model is however too unrealistic to reproduce the behaviour in the $\mathrm{Cu}-\mathrm{Au}$ system, where the band separation is small.

4. Conclusions. - The measured concentration dependence of the absorption edge in $\mathrm{Cu}-\mathrm{Ag}$ alloys is in agreement with the «two overlapping band " model shown in figure 4. A reexamination of the data of the $\mathrm{Ag}-\mathrm{Au}$ and $\mathrm{Cu}-\mathrm{Au}$ systems shows that the same model can be applied to these alloys. CPA calculations, using the model by Schwartz et al., can reproduce the observed behaviour in the $\mathrm{Cu}-\mathrm{Ag}$ system but not in the $\mathrm{Cu}-\mathrm{Au}$ system.

\section{References}

[1] Maler, S., Nowick, A. S. and Widmer, H., Acta Met. 15 (1967) 203.

[2] Nilsson, P. O., Appl. Opt. 7 (1968) 435.

[3] For $\mathrm{Cu}$ see e. g. Fong, C. Y., Cohen, M. L., ZuCCA, R. R: L., Stockes, J. and Shen, Y. R., Phys. Rev. Lett. 25 (1970) 1486.

[4] For Ag see e. g. Christensen, N. E., Phys. Stat. Sol. (b) 54 (1972) 551 ; LILJENVAll, H. G. and MatheWson, A. G., J. Phys. C, Suppl. 3 (1970) 341.

[5] Beaglehole, D. and Erlbach, E., Solid State Commun. 8. (1970) 255 and Phys. Rev. B 4 (1972) 1209.

[6] Soven, P., Phys. Rev. 178 (1969) 1136.

[7] Levin, K. and Ehrenreich, H., Phys. Rev, B 3 (1971) 4172.

[8] Rivory, J., Optics Commun. 1 (1969) 53.
[9] Wessel, P. R., Phys. Rev. 132 (1963) 2062.

[10] Fukutani, H. and Sueoka, D., in «Optical Properties Electronic Structure of Metals and Alloys», edited by F. Abelès (North-Holland Publishing Company, Amsterdam) 1966.

[11] Koester, W. and StahL, R., Z. Metallkde 58 (1967) 768.

[12] Stern, E. A., Phys. Rev. 144 (1966) 545.

[13] Nilsson, P. O. and Forssell, G., to be published.

[14] Nil.sson, P. O., Physik kondens. Materie 11 (1970) 1.

[15] Nilsson, P. O., Persson, A. and Hagström, S., Solid State Commun. 6 (1968) 297.

[16] Schwartz, L., Brouers, F., VedyayeV, A. V. and EhrenREICH, H., Phys. Rev. B 4 (1971) 3383. 